\title{
Linking strategic improvisation and entrepreneurial self-efficacy to corporate entrepreneurship in Nigerian higher education institutions (HEIs)
}

\author{
Najafi Auwalu Ibrahim ${ }^{a b^{*}}$, Rosli Mahmood ${ }^{a}$ and Muhammad Shukri Bakar ${ }^{a}$
}

${ }^{a}$ School of Business Management, Universiti Utara Malaysia, 06010 UUM Sintok, Kedah Darul Aman, Malaysia ${ }^{b}$ Department of Business Administration and Entrepreneurship, Bayero University, Kano, Nigeria

\section{CH R O N I C L E \\ A B S T R A C T}

Article history:

Received June 5, 2016

Received in revised format

October 2, 2016

Accepted October 26, 2016

Available online

October 27, 2016

\section{Keywords:}

Corporate entrepreneurship

Entrepreneurial self-efficacy

Higher Education Institutions (HEIs)

Strategic improvisation

\begin{abstract}
The role of leaders toward the development of entrepreneurship has been fully acknowledged. However, Leaders' characteristics such as strategic improvisation and entrepreneurial selfefficacy were mainly examined in the private sector. Hence, it is imperative to extend empirical studies to public sector organizations. The present study, therefore, proposed and validated a model linking leaders' strategic improvisation and entrepreneurial self-efficacy to corporate entrepreneurship in Nigerian Higher Education Institutions (HEIs). Using a structured questionnaire, 220 responses were generated from large HEIs in Kano State, Nigeria. The data of the study was analyzed using SmartPLS 3.0 to ascertain both measurement and structural model validity of the model. The results showed that both leaders' strategic improvisation and entrepreneurial self-efficacy were significantly related to corporate entrepreneurship in HEIs. Implication and limitation of the study; and suggestions for future study are also provided.
\end{abstract}

\section{Introduction}

The pressure for change in public sector organizations has cut across almost all continents and sectors (Blackmore \& Sawers, 2015; Yadav \& Dabhade, 2013), including Higher Education Institutions (HEIs) (Bakar, 2014). The HEIs in Nigeria are facing similar pressure to increase efficiency, effectiveness and performance. These institutions have been accused of neglecting the changes that occur in the environment, which resulted in producing unskilled graduates that find it difficult to get jobs. While HEIs have been attributed to economic growth and development in other countries, HEIs in Nigeria are out-dated and not in line with the need of the society. These problems have been linked with the old traditional method of bureaucracy, rigidity, centralization and ambiguity in terms of power and responsibility (Nayyar \& Mahmood, 2014), not to mention the rapid change that occurs in today's environment. Moreover, Dike (2014) reported that poor funding, obsolete facilities and dearth of skilled personnel have also played a role in the situation HEIs found themselves. However, all these problems associated with HEIs have been attributed to poor leadership that has the ability and skills to prioritize the limited available resources found at their disposal. Hence the need to identify relevant changes, that 
are capable of turning things around faster and better than their competitors or rivals (Cunha et al., 2012).

The significance of organizational changes or renewal for Nigerian HEIs, currently demonstrated a greater impact for their development. These changes provided an avenue for rejuvenating these institutions for increase performance and sustainability. One of the methods through which this renewal can be achieved is through corporate entrepreneurship (CE). Corporate entrepreneurship has been defined as those behaviours and activities display by individuals in established organizations (Holt et al., 2007). Important to realize is that several studies have established the link between corporate entrepreneurship and performance (Bakar \& Mahmood, 2014; Simsek et al., 2011). However, less attention has been given to factors leading to corporate entrepreneurship especially in HEIs. Specifically, Kiani Mavi et al. (2016) stated that studies on corporate entrepreneurship often neglect interrelationship that exists between individual, environment and organizational factors. In addition, internal factors such leaders' characteristics have been neglected despite their role been acknowledged as one of the key factors that influence corporate entrepreneurship (Heavey \& Simsek, 2013; Mustafa et al., 2016). The present study, therefore, investigated the relationship between leaders' strategic improvisational behaviour, entrepreneurial self-efficacy and corporate entrepreneurship.

\section{Literature review and hypotheses development}

\subsection{Leaders' Strategic improvisation and corporate entrepreneurship}

Strategic improvisation is one of the new concepts that enhance competitive advantage for organizations struggling to survive today's turbulent environment because it allows flexibility and adaptability (Bakar et al., 2015; Vera \& Crossan, 2005). Strategic improvisation has been defined as the ability to spontaneously recombine knowledge, processes and structure in real time, resulting in creative problem solving that is grounded in the realities of the moment (McKnight \& Bontis, 2002). In this study, strategic improvisation is defined as leaders' ability to respond to unforeseen circumstances intelligently and effectively in order to solve a problem or utilize an opportunity. In essence, strategic improvisation is processes were planning and action is strategically exhibited at the emergent of behaviour.

Several studies have justified the link between strategic improvisation and corporate entrepreneurship or its elements. For example, Brown and Eisenhardt (1997) have established that improvisation plays an important role in successful innovation and strategic renewal. Similarly, Vera and Crossan (2005) also revealed that improvisation is positively related to organizational innovativeness, especially if combined with some external factors. In essence, studies have linked improvisation with starting a new business (Baker, Miner, \& Eesley, 2001; Hmieleski \& Corbett, 2006) and new venture (Hmieleski \& Corbett, 2008), which are all part and parcel of corporate entrepreneurship. Hence, the study postulates that:

$\mathrm{H}_{1}$ : Leaders' strategic improvisation is positively related to corporate entrepreneurship in Nigerian higher education institutions.

\subsection{Entrepreneurial self-efficacy and corporate entrepreneurship}

Self-efficacy is one of the most dominant factors explaining the reason people pursue specific given tasks with the zeal to succeed at all cost (Bandura, 1997). Hence, the conclusion that the main motivating factor lies not in the objective assessment but rather the subjective one, which is the inner perceived individual self-belief (Markman et al., 2002). However, ESE has been defined as the inner strength of an individual that pushes someone to successfully engage in entrepreneurial activities and tasks (Boyd \& Vozikis, 1994). Leaders with high entrepreneurial self-efficacy are more likely to identify and utilize entrepreneurial opportunities as well as outcome such as corporate entrepreneurship (Chen et al., 1998; Fiet, 2002). 
The relationship between ESE and individual entrepreneurial intention is well documented (Hallak et al., 2012; Naktiyok et al. 2010), likewise, the linked between ESE and new venture creation, renewal and growth (Jung et al. 2001; Marta et al., 2016). For example, Naktiyok et al., (2010) conducted a study in turkey where they established the linked between ESE and intention to start a new business. In a similar study Jung et al. (2001) also established that ESE has a significant and positive relationship with new business intention and action. Hence, the study postulates that:

$\mathrm{H}_{2}$ : Entrepreneurial self-efficacy is positively related to corporate entrepreneurship in Nigerian higher education institutions.

\section{Research methodology}

The study adopted a quota sampling, which is considered as a form of proportionate stratified sampling technique (Sekaran \& Bougie, 2013). The use of the technique is premised on the fact that the sample are from different sub-groups with different numbers. The study in determining the population of the study that cut across ten higher institutions in Kano state, adopted Dillman (2007) method by selecting 370 out of 756 samples. The selection was based on strata in which all the ten tertiary institutions were included. The questionnaire was adapted from previous studies, SI from Vera and Crossan (2005), ESE from Wilson et al. (2007) and CE from Covin and Slevin (1989) respectively. The 100\% questionnaires were distributed within a period of three months, out of which only $62 \%$ response was received. The questionnaire is divided into four sections namely: corporate entrepreneurship, strategic improvisation, entrepreneurial self-efficacy and lastly the demographic section. Questions (statements) were set on a five-point Likert scale ranging from strongly agree (5) to strongly disagree (1) aimed to determine their level of acceptance on the construct of the study.

\section{Result and discussions}

The data generated was analysed using Partial Least Square (PLS) version 3.0, which was divided into two basic sections. The measurement model and the structural model are the two steps of analysing data using structural equation modelling (SEM) as suggested by Hair et al. (2013) and Henseler et al. (2009).

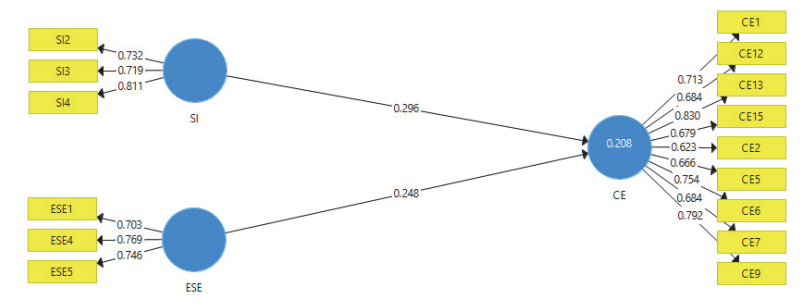

Fig. 1. Measurement model

The measurement model presented in Fig. 1 above provided confirmatory factor analysis (CFA) of the model. It includes individual item reliability, convergent and discriminant validity of the measures. Consequently, a bootstrapping techinque was applied to determine the level of significance for the loadings, weights, and path coefficients as suggested by Chin (1998). Hence, the establishment and validation of the measurement model. Table 1, 2, and 3 provided values that are higher than the threshold suggested in the literature. Specifically, internal consistency values were all above 0.50 threshold (Anderson \& Gerbing, 1988; Bagozzi \& Yi., 1998; Gefen \& Straub, 2005). Similarly, convergent validity values of both composite reliability (CR) and average variance extracted (AVE) were all above 0.70 and 0.50 as suggested by Henseler et al. (2009) and Vinzi et al. (2010). 
The final validity of the measurement model for the discriminant validity was evaluated using three different methods. The most common method of validating the discriminant validity as suggested by Hair et al. (2010) and Fornell and Larcker (1981) has been cross loadings criteria. The cross loading is a process were the construct items loads better in the mother construct than in another construct of the study, while, the Fornell and Larcker (1981) criteria expect the square root of the AVE to be higher than when interrelating to the other construct. In essence, the only difference between cross-loadings and the AVE method, the later validate at the construct level while the former validate at the item level. All the values presented in Table 1 have achieved cross-loadings and AVE discriminant validity. Nevertheless, these methods was recently criticized by Henseler et al. (2015), that in most cases the above methods fails to fully scrutinize and validate the issue of discriminant validity. They, however, suggested the multitrait-multimethod matrix, to assess discriminant validity, the heterotrait-monotrait (HTMT) ratio of correlations as a more rigorous method of achieving discriminant validity. Henseler et al. (2015) stated that using HTMT.85 values most not be greater than .85 (Kline, 2011). Hence, discriminant validity may not a problem looking at the values stated in Table 3 .

Table 1

Construct validity and reliability

\begin{tabular}{llccc}
\hline Constructs & Items & Loadings & AVE & Composite reliability \\
\hline Corporate entrepreneurship & CE1 & 0.713 & & \\
& CE12 & 0.684 & & \\
& CE13 & 0.830 & & $\mathbf{0 . 9 0 4}$ \\
& CE15 & 0.679 & & \\
& CE2 & 0.623 & $\mathbf{0 . 5 1 3}$ & \\
& CE5 & 0.666 & & \\
& CE6 & 0.754 & & $\mathbf{0 . 7 8 4}$ \\
& CE7 & 0.684 & & \\
& CE9 & 0.792 & & $\mathbf{0 . 7 9 9}$ \\
\hline \multirow{2}{*}{ Entrepreneurial self-efficacy } & ESE1 & 0.703 & & \\
& ESE4 & 0.769 & $\mathbf{0 . 5 4 7}$ & \\
& ESE5 & 0.746 & & $\mathbf{0 . 5 7 1}$ \\
\hline
\end{tabular}

Table 2

Discriminant validity

\begin{tabular}{lrrrr}
\hline & CE & ESE & SI \\
\hline CE & $\mathbf{0 . 7 1 7}$ & & \\
ESE & 0.365 & $\mathbf{0 . 7 4 0}$ & \\
SI & 0.394 & 0.395 & $\mathbf{0 . 7 5 5}$ \\
\hline
\end{tabular}

Table 3

Heterotrait-monotrait (HTMT)

\begin{tabular}{lrrr}
\hline & CE & ESE & SI \\
\hline CE & & & \\
ESE & 0.488 & \\
SI & 0.491 & 0.637 \\
\hline
\end{tabular}

Shaded boxes are the standard reporting format for HTMT procedure

The structural model in Figure 2 provided a justification for the postulated hypotheses for this present study. Precisely, the structural model aimed at assessing hypotheses, R-square, effect size and the predictive relevance of the model. The present study has R-square value of $21 \%$, which states how well the exogenous constructs have explained the endogenous construct. The value of $0.208(21 \%)$ can be categorized as moderate according to Chin (1998), by classifying R2 into three namely $19 \%, 33 \%$ and $67 \%$ to represent small, medium and large respectively. 


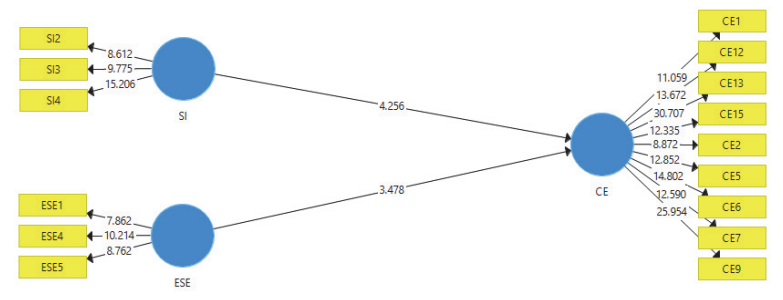

Fig. 2. Structural model

\section{The structural model}

The hypotheses result of the study in Table 4 presented an evaluation of the path model of the structural model in fig. 2 above. The result provided empirical justification for all the hypotheses. Specifically, the study hypothesized positive relationship between strategic improvisation and corporate entrepreneurship in HEIs. The result was accepted with a beta value of 0.248 , t-value 3.589 at significant level of $1 \%$ (p-value $=0.000)$. In the same vein entrepreneurial self-efficacy also has a positive and significant relationship with corporate entrepreneurship in HEIs. In this case, the findings showed a beta value of $0.296, \mathrm{t}$ value 4.295 at significant level of $1 \%(\mathrm{p}$-value $=0.000)$. Therefore, all the two hypotheses of the study cannot be rejected.

\section{Table 4}

Summary of findings

\begin{tabular}{ccccccc}
\hline Hypotheses & Path & Beta & Standard Deviation & T Statistics & P Values & Decision \\
\hline H1 & ESE -> CE & 0.248 & 0.069 & $3.589^{* * *}$ & 0.000 & Accepted \\
H2 & SI -> CE & 0.296 & 0.069 & $4.295^{* * *}$ & 0.000 & Accepted \\
\hline *** Significant at 0.001 (1 tailed) & & & &
\end{tabular}

To assess effect size $\left(\mathrm{f}^{2}\right)$ Hair et al. (2013) submission was adopted, they argued that result (p-value) only indicates significance of the relationship and not the effect of individual construct. Hence, creating serious concern on data and result interpretation, as such, the need to examine change in $\mathrm{R}^{2}$ after deleting a construct to understands its effect. According to Cohen (1988) effect size are classified into 0.35 large, 0.15 medium and 0.02 small. The $\mathrm{f}^{2}$ value of the study is 0.093 for SI and 0.066 for ESE, falling into the smaller effect category. This means, the variables are within the accepted limit. Finally, to fully meet the requirement of the structural model a blindfolding procedure was carried out to evaluate the predictive relevance $\left(\mathrm{Q}^{2}\right)$ of the whole model. The main reason for conducting blindfolding test was to determine how well the model and its estimate were structured in the study. Hence, a model could be reported to have a predictive relevance if the result of the blindfolding is greater than zero (Chin, 1998). The present study has a value of 0.094 which is greater than zero. Conclusively, it can be said that the model has a predictive relevance.

Table 5

$\mathrm{Q}^{2}$ Predictive relevance

\begin{tabular}{rrrr}
\hline Total & SSO & SSE & 1-SSE/SSO \\
\hline CE & 1980 & 1794518 & 0.094 \\
\hline
\end{tabular}

\section{Discussion and conclusion}

We argued that leaders' characteristics, namely SI and ESE are important factor that will help in revitalizing HEIs in Nigeria. Specifically, we argued that individual plays a significant role in opportunity recognition and utilization for the benefits of the organisation if given the opportunity, 
hence, the birth of CE. The CE has been regarded as the driving factor that determines the future of any organization (see., Elia et al., 2016; Guth \& Ginsberg, 1990; Ireland et al., 2009), because in CE organization finds adaptability through innovativeness and strategic renewal. The HEIs are important sector of the economy, not to mention their role in determining the type of work force of an organization and the Nation at large. Studies on CE mainly focuses on external factors (Zahra, 1991), hence, ignoring the impact of middle line managers who are responsible for organizational strategy implementation. In fact contemporary researchers (see., Kakapour et al., 2016; Bakar et al., 2016) have identified the need for studies on individual factors as antecedence of corporate entrepreneurship.

Consequently, the study provided empirical support for the effect of leaders' strategic improvisation, entrepreneurial self-efficacy on corporate entrepreneurship. The study as one of the pioneering studies attempted to test the relationship between strategic improvisation, entrepreneurial self-efficacy and corporate entrepreneurship in public sector, precisely the HEIs. The results are similar to findings obtained in the private sector, in which this relationship was found to be positive and significant to either entrepreneurial intention or strategic renewal and firm performance. Thus, provides an additional literature on antecedence of $\mathrm{CE}$, especially in the public domain. Based on the findings from this study, we recommended that HEIs management should double their effort in recognizing and appreciating leaders' with these characteristics, as it will not only result to CE but also improve performance of the whole institutions. In addition, programs should be design were these characteristics can be developed and maintained for the use of the institutions. However, future studies can extend this result in other public sector domain and can also look at the individual effects as antecedence of corporate entrepreneurship. In addition, a comparative analysis can also be looked at where both individual and organisational factors are identified as antecedence of CE in Nigeria HEIs.

\section{References}

Anderson, J. C., \& Gerbing, D. W. (1988). Structural equation modeling in practice: A review and recommended two-step approach. Psychological Bulletin, 103(3), 411-423.

Bagozzi, \& Yi., Y. (1998). On the evaluation of structural equation models. Journal of the Academy of Marketing Science, 16(1), 74-94.

Bakar, H. A., Mahmood, R., \& Ismail, N. N. H. (2015). Effects of Knowledge Management and Strategic Improvisation on SME Performance in Malaysia. Asian Social Science, 11(9), p207. JOUR.

Bakar, M. S. (2014). Mediating effect of intrapreneurial orientation on the relationship between leadership style, knowledge sharing behavior and performance of academic leaders in Malaysia. University Utara Malaysia.

Bakar, M. S., \& Mahmood, R. (2014). Linking Transformational Leadership and Corporate Entrepreneurship to Performance in the Public Higher Education Institutions in Malaysia. Advances in Management and Applied Economics, 4(3), 109. JOUR.

Baker, T., Miner, A. S., \& Eesley, D. T. (2001). Fake it until you make it, and then... Planning Theory, 10(3), 201-212.

Blackmore, J., \& Sawers, N. (2015). Executive power and scaled-up gender subtexts in Australian entrepreneurial universities. Gender and Education, 27(3), 320-337.

Boyd, N. G., \& Vozikis, G. S. (1994). The influence of self-efficacy on the development of entrepreneurial intentions and actions. Entrepreneurship Theory and Practice, 18, 63. Journal Article.

Brown, S. L., \& Eisenhardt, K. M. (1997). The Art of Continuous Change : Linking Complexity Theory and Time-Paced Evolution in Relentlessly Shifting Organizations, 42(1), 1-34.

Chen, C. C., Greene, P. G., \& Crick, A. (1998). Does entrepreneurial self-efficacy distinguish entrepreneurs from managers? Journal of Business Venturing, 13(4), 295-316.

Chin, W. W. (1998). Commentary: Issues and Opinion on Structural Equation Modeling. MIS Quarterly, 22(1), 7-16. 
Cohen, J. (1988). Statistical power analysis for the behavioral sciences. Statistical Power Analysis for the Behavioral Sciences.

Covin, J. G., \& Slevin, D. P. (1989). Strategic management of small firms in hostile and benign environments. Strategic Management Journal, 10(1), 75-87. JOUR. Retrieved from http://papers.ssrn.com/abstract $=1505210$

Cunha, M. P. E., Clegg, S. R., \& Kamoche, K. (2012). Improvisation as "real time foresight." Futures, 44(3), 265-272.

Dillman, D. A. (2007). Mail and internet serveys: The tailored design method (Vol. 2).

Dike, V. E. (2014). Leadership and the Nigerian Economy. SAGE Open, 4(1), 10. JOUR.

Elia, G., Margherita, A., \& Petti, C. (2016). Corporate Entrepreneurship: The Antecedents at Individual and Organisational Levels in Technology-Based Firms. In Creating Technology-Driven Entrepreneurship (pp. 49-77).

Fiet, J. (2002). The systematic search for entrepreneurial discoveries. Retrieved from https://books.google.com.my/books?hl=en\&lr=\&id=n1d3h03sy9gC\&oi=fnd\&pg=PR9\&dq=The+ Systematic+Search+for+Entrepreneurial+Discoveries\&ots=vqsiib1GnC\&sig=uViiXQfHJSF_M5yHZGF_FVwKYI

Fornell, C., \& Larcker, D. (1981). Evaluating structural equation models with unobservable variables and measurement error. Journal of Marketing Research, 18(3), 39-50.

Gefen, D., \& Straub, D. (2005). A Practical Guide To Factorial Validity Using PLS- Graph : Tutorial And Annotated Example. Communications of the Association for Information Systems, 16(5), 91109.

Guth, W. D., \& Ginsberg, A. R. I. (1990). Guest editors' introduction: Corporate entrepreneurship. Strategic Management Journal, 11(4), 5-15.

Hair, J. F., Black, W. C., Babin, B. J., \& Anderson, R. E. (2010). Multivariate Data Analysis. Vectors (7th ed.). Edinburgh: Pearson Education Limited.

Hair, J. F. J., Hult, G. T. M., Ringle, C., \& Sarstedt, M. (2013). A Primer on Partial Least Squares Structural Equation Modeling (PLS-SEM). Long Range Planning (Vol. 46). Thousand Oaks, CA: SAGE Publications, Incorporated.

Hair, J. F., Ringle, C. M., \& Sarstedt, M. (2013). Partial Least Squares Structural Equation Modeling: Rigorous Applications, Better Results and Higher Acceptance. Long Range Planning, 46(1-2), 112.

Hallak, R., Assaker, G., \& O’Connor, P. (2012). Are Family and Nonfamily Tourism Businesses Different? An Examination of the Entrepreneurial Self-Efficacy-Entrepreneurial Performance Relationship. Journal of Hospitality \& Tourism Research, 20(10), 1-26.

Heavey, C., \& Simsek, Z. (2013). Top management compositional effects on corporate entrepreneurship: The moderating role of perceived technological uncertainty. Journal of Product Innovation Management, 30(5), 837-855.

Henseler, J., Ringle, C. M., \& Sarstedt, M. (2015). A new criterion for assessing discriminant validity in variance-based structural equation modeling. Journal of the Academy of Marketing Science, 43(1), 115-135.

Henseler, J., Ringle, C. M., \& Sinkovics, R. R. (2009). Advances in International Marketing. Advances in International Marketing, 20, 277-319.

Hmieleski, K. M., \& Corbett, A. C. (2006). Proclivity for improvisation as a predictor of entrepreneurial intentions. Journal of Small Business Management, 44(1), 45-63.

Hmieleski, K. M., \& Corbett, A. C. (2008). The contrasting interaction effects of improvisational behavior with entrepreneurial self-efficacy on new venture performance and entrepreneur work satisfaction. Journal of Business Venturing, 23(4), 482-496.

Holt, D. T., Rutherford, M. W., \& Clohessy, G. R. (2007). Corporate Entrepreneurship: An Empirical Look at Individual Characteristics, Context, and Process. Journal of Leadership \& Organizational Studies, 13(4), 40-54.

Ireland, R. D., Covin, J. G., \& Kuratko, D. F. (2009). Conceptualising Corporate Entrepreneurship Strategy. Entrepreneurship Theory and Practice, (979), 19-47. 
Jung, D. I., Ehrlich, S. B., De Noble, A. F., \& Baik, K. B. (2001). Entrepreneurial self-efficacy and its relationship to entrepreneurial action: A comparative study between the US and Korea. Management International, Vol. 6(1), 41-53. JOUR. Retrieved from http://scholar.google.com/scholar?hl=en\&btnG=Search\&q=intitle:Entrepreneurial+Self+Efficacy+ and + its + Relationship + to + Entrepreneurial + Action: $+\mathrm{A}+$ Comparative + Study + Between + the + US + an $\mathrm{d}+$ Korea\#0

Kakapour, S., Morgan, T., Parsinejad, S., \& Wieland, A. (2016). Antecedents of corporate entrepreneurship in Iran: the role of strategic orientation and opportunity recognition. Journal of Small Business \& Entrepreneurship, 28(3), 251-266.

Kiani Mavi, R., Kiani Mavi, N., \& Goh, M. (2016). Modeling corporate entrepreneurship success with ANFIS. Operational Research. http://doi.org/10.1007/s12351-015-0223-8

Markman, G., Balkin, D., \& Baron, R. A. (2002). Inventors and New Venture Formation: the Effects of General Self-Efficacy and Regretful Thinking. Theory and Practice, 27(2), 149-166.

Marta, D. M., Carlos, E. J., Ángel, F. M., Marta, D. M., Carlos, E. J., \& Ángel, F. M. (2016). Marketing self-efficacy and firm creation. Journal of Small Business and Enterprise Development, 23(1), 90104.

Mustafa, M., Martin, L., \& Hughes, M. (2016). Psychological Ownership, Job Satisfaction, and Middle Manager Entrepreneurial Behavior. Journal of Leadership \& Organizational Studies, 1-16.

Naktiyok, A., Karabey, C. N., \& Gulluce, A. C. (2010). Entrepreneurial self-efficacy and entrepreneurial intention: the Turkish case. International Entrepreneurship and Management Journal, 6(4), 419-435. JOUR.

Nayyar, J., \& Mahmood, R. (2014). The Effect of Corporate Entrepreneurship Determinants on Performance of Public Higher Education Institutions in Pakistan. Business \& Entrepreneurship Journal, 3(1), 19-31.

Sekaran, U., \& Bougie, R. (2013). Research methods for business: A skill-building approach, Fourth edition. John Wiley and Sons, New York. Retrieved from http://eu.wiley.com/WileyCDA/WileyTitle/productCd-111994225X.html

Shukri Bakar, M., Mahmood, R., Ramli, A., \& Saad, R. M. (2016). Knowledge Sharing Behaviour and Performance of Academic Leaders: Mediating Role of Corporate Entrepreneurship. Middle-East Journal of Scientific Research, 24(6), 2028-2035.

Simsek, Z., Heavey, C., Nicolaou, N., Shane, S., Cherkas, L., \& Spector, T. (2011). The mediating role of knowledge-based capital for corporate entrepreneurship effects on performance: a study of smallto medium-sized firms. Strategic Entrepreneurship Journal, 5(1), 81-100.

Vera, D., \& Crossan, M. (2005). Improvisation and Innovative Performance in Teams. Organization Science, 16(3), 203-224.

Vinzi, E. V., Chin, W. W., Henseler, J., \& Wang, H. (2010). Handbook of Partial Least Squares Concepts, Methods and Application. (J. E. Gentle, W. K. Härdle, \& Y. Mori, Eds.), Methods. Springer.

Wilson, F., Kickul, J., \& Marlino, D. (2007). Gender, entrepreneurial self-efficacy, and entrepreneurial career intentions: Implications for entrepreneurship education. Entrepreneurship: Theory and Practice, 31(3), 387-406.

Yadav, R., \& Dabhade, N. (2013). Performance management system in Maharatna Companies (a leading public sector undertaking) of India-a case study of BHEL, Bhopal (MP). International Letters of Social and Humanistic ..., 4, 49-69.

Zahra, S. A. (1991). Predictors and financial outcomes of corporate entrepreneurship: An exploratory study. Journal of Business Venturing, 6(4), 259-285.

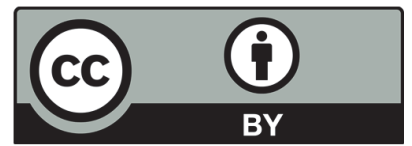

(C) 2016 by the authors; licensee Growing Science, Canada. This is an open access article distributed under the terms and conditions of the Creative Commons Attribution (CC-BY) license (http://creativecommons.org/licenses/by/4.0/). 